\title{
BODY IMAGE DISTURBANCE AND RELATIONSHIP SATISFACTION BETWEEN OBESE AND NON-OBESE MARRIED WOMEN
}

\author{
Shazia Hasan', Mehwish Zafar², Rabia Yasmeen ${ }^{3 凶}$
}

\section{ABSTRACT}

OBJECTIVE: To determine body image disturbance and relationship satisfaction between obese and non-obese married women.

METHODS: Study sample consisted of 100 participants. Data was collected through purposive sampling technique from different gyms and nutrient-clinics of Johar Town, Faisal Town and Model Town of Lahore city. Educated females having minimum education level of intermediate belonging to upper and middle-class families were recruited. The shortened form of Body Shape Questionnaire and Relationship Assessment Scale were administered, in addition to collecting demographic information through a semi structure performa. Independent sample t-test and Pearson's Product-Moment Correlation was used in the analysis of the data, using SPSS v.21.

RESULTS: Most of obese and non-obese married women $(n=41 / 50)$ were in the age range of 25-35 years and 30-40 years respectively with mean age of 34 years for obese and 33 years for non-obese married women. Husband's mean age for obese and non-obese was 39 years and 38 years respectively. Almost all the non-obese $(n=49 / 50)$ while most of the obese $(n=39 / 50)$ married women were having education level of 16 or more while almost all the non-obese $(n=48 / 50)$ were working women and most $(n=40 / 50)$ of the obese were house wives. Thirty-two $(32 / 50)$ non-obese were having 2-6 years while $(n=29 / 50)$ obese married women were having 7-9 years of marriage duration. A significant relationship was shown at the level of body image disturbance $(p<0.000)$ and marital satisfaction $(p<0.000)$ between obese and non-obese married women.

CONCLUSION: Obesity has significant impact on body image and relationship satisfaction in married women.

KEY WORDS: Obesity (MeSH); Body Mass Index (MeSH); Personal Satisfaction (MeSH); Body image disturbance (Non-MeSH); Relationship Satisfaction (Non-MeSH); Body shape questionnaire (Non-MeSH); Relationship assessment scale (Non-MeSH); Women (MeSH).

THIS ARTICLE MAY BE CITED AS: Hasan S, Zafar M, Yasmeen R. Body image disturbance and relationship satisfaction between obese and nonobese married women. Khyber Med Univ J 2019;II(I):2I-5. DOI:I0.35845/kmuj.2019.1803।.

\section{INTRODUCTION}

R ecently, obesity is known as one of the top ten global problems. A welldefined explanation of obesity considered as excessive and abnormal fat, which is a risk factor for health.' Obesity can be explained in terms of body mass index (BMI), which is measured by dividing a person's weight $(\mathrm{kg})$ to his or her height $\left(\mathrm{m}^{2}\right)$. The standard normal female's weight is considered non-obese from 18.5 to 24.9 , while mild obesity is 25.5 to 29.9 and moderate obesity is 29.30 to 30.9 and individuals with $\mathrm{BMI}$ of $3 \mathrm{I}-40$ or more are generally considered as severe obese. The main problem is related to high level of BMI which can impact on women's feelings and thoughts about their appearance. ${ }^{2}$ Unfortunately, there are persistent social pressures to be slim for obese girls and married obese women in every
I Professor, Department of Psychology, University of Central Punjab, Lahore, Pakistan.

2 Clinical Psychologist, Ehsas Clinic: Addiction and Psychological Treatment Centre, Lahore, Pakistan.

3 Research Associate, Department of Psychology, University of Central Punjab, Lahore, Pakistan.

Email『: rabia.akram22@gmail.com

Date Submitted:

Date Revised:

November 29, 2017

Date Accepted:

March 13, 2019

March 19, 2019

culture because slimness is considered as the form of beauty and attraction whereas obesity is strongly rejected. Moreover, obese women have negative evaluations with their own body image parts such as stomach, hips, breast size and buttocks. ${ }^{3,4}$ The body image construct has dynamic approach, which contains internal factors i.e. psychological and biological elements with external factors i.e. social and cultural. ${ }^{5}$ Link between body image and obesity creates a disturbance which lead towards negative thinking and feelings about self. According to the Global Burden of Disease Study, women obesity rate has increased as compared to males in Pakistani population as Pakistan is ranked on $9^{\text {th }}$ number out of 188 countries in terms of obesity. ${ }^{6}$

According to the biological perspective, obesity in married women is generally the process of primary metabolic system, whereas some women genetically report obesity or extreme fatness. Moreover, physiological process and behavioral activities (overeating) cause excessive fatness, which is considered as obese. ${ }^{7}$ Behavior theory view excessive eating leading to obesity as an over learned habit strongly conditioned to internal and external cues. Whereas, learned behaviors of childhood is the reflection of adulthood obesity. ${ }^{8}$ In Social Cognitive Theory, Bandura proposed that the nature of human health based on their personal (thoughts), behavioral (natural actions) and environmental aspects, obese women have negative thoughts about body image that indulge them in physical actions (excessive fasting, exercise) to reduce social stigmatization.

Most of obese married females have 
TABLE I: DEMOGRAPHIC CHARACTERISTICS OF OBESE AND NON-OBESE MARRIED WOMEN

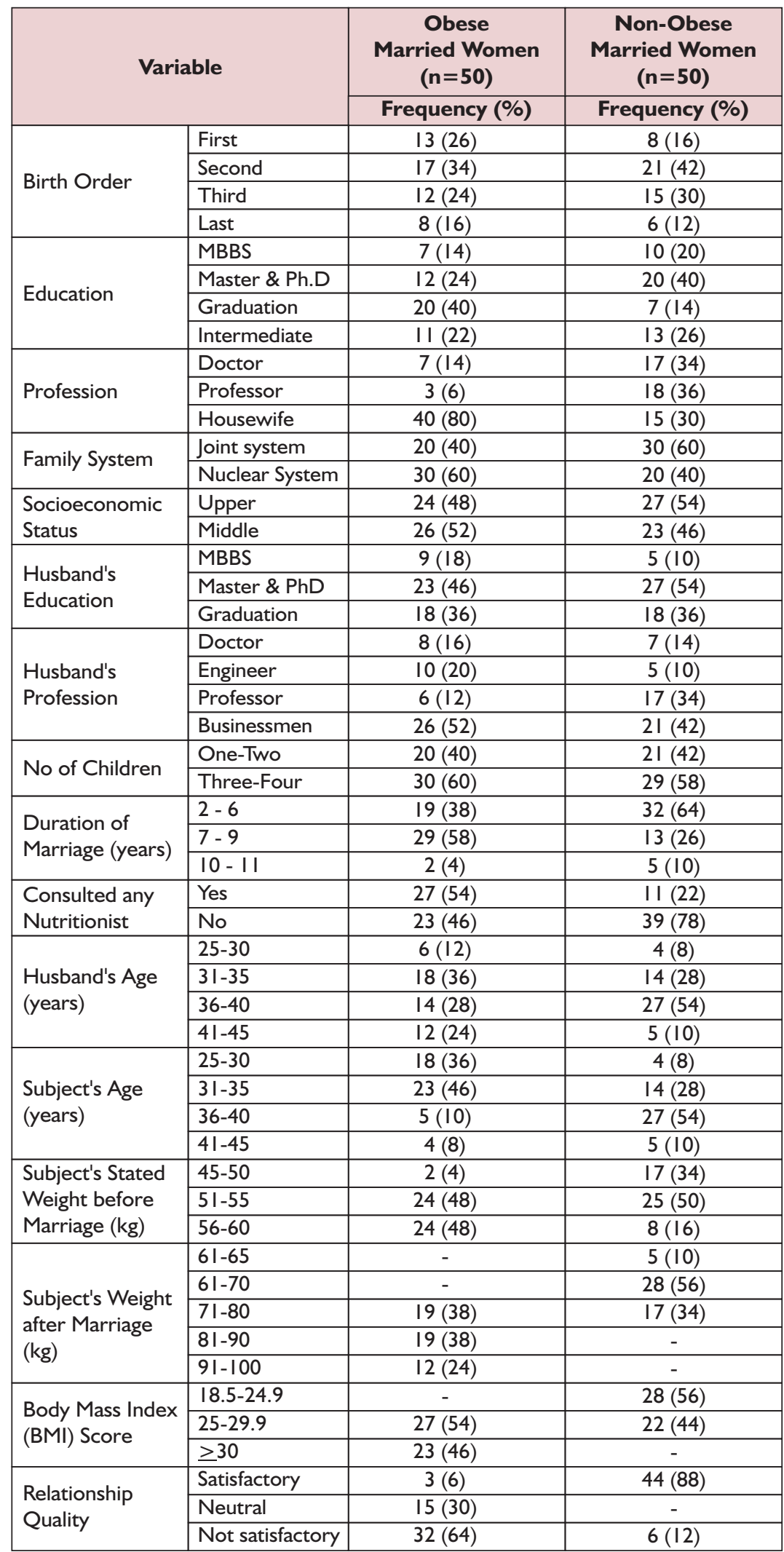

issues related to their body shape and size and feedback from peers, family members and life partners. This feedback may involve negative distorted thoughts about self-appearance and has extreme influence on their relationship satisfaction and their self-esteem. ${ }^{10}$ Literature suggested that its prevalence ranges from $10 \%$ to $50 \%$ of the population and $50 \%$ to $88 \%$ of females feel uncomfortable about their body shape or size after receiving criticism from close relationships and negative feedback is increasing day by day. "'

Research has proved that physical attractiveness plays a vital role in marital satisfaction. Life partner's satisfaction about their spouse's physical appearance is one of most important elements for marital satisfaction. Results concluded that spouses behaved more positively in a relationship in which wives were attractive than their husbands. ${ }^{12}$ Moreover, displeasure in romantic relationship has direct impact on marital satisfaction of obese married women. $^{13}$ The criticism of romantic partners on their wives physical appearance led them toward low level of marital satisfaction. Resultantly the obese females try to control their weight in effort to fulfill the standard expectations of their life partner. These endure efforts or sometime failure in reducing weight cause emotional instability. ${ }^{14}$ Emotional instability has impact on cognition of obese females which usually presents like obsessive self-scrutiny in mirror and thinking disparaging when perceiving negative comments from their close relationships (spouse, friends and family) on self-appearance. ${ }^{15}$

Obesity is prevalent in our society which may cause problems related to self-image/body image and relationship satisfaction. This research was planned to find out the effect of body weight towards problems in marital satisfaction which may lead to problems in family system that can result in psychopathologies. Understanding the problem of obesity will develop insight, it will also help mental health professionals and family counselors to develop management plan for their therapeutic interventions. 


\section{METHODS}

This research was a cross-sectional study and it was conducted in three months of time duration. Purposive sampling technique was used to collect data for this study. The study consisted of 100 females $(n=100)$, 50 obese married females and 50 non-obese married females. The age range of research sample was 25 to 50 years. Research sample was obtained from different gyms and nutrient clinics of three different towns (Johar Town, Faisal Town and Model Town) of Lahore city. Educated females were recruited; minimum education level was intermediate and they belonged to upper and middle class families.

Firstly, research synopsis was approved for conducting research by the Institute Research Committee, University of Central Punjab. After taking the permission from the concerned authorities data was collected. Participants were briefed about the purpose of study, informed consent was signed from each participant and they were assured about confidentiality of information. After which a demographic form and scales were given to participants. Results were analyzed using Statistical Package for Social Sciences (SPSS 21 -Version). Independent sample t-test and Pearson's Product-Moment Correlation were applied to measure the significant results.

Two different tools were applied. The first one was Body Shape Questionnaire

${ }^{16}$ (shortened form) of 34-items and scored from I-6; never for I and always for 6. It consists of individual personal reported form of measure which indicates worries about body image. It has $0.98 \mathrm{I}$ Cronbach's alpha reliability coefficient, BMI used in this questionnaire is a value that is sometimes calculated the weight in kilograms divided by square height in meter. ${ }^{17}$ The second one was Relationship Assessment Scale ${ }^{18}$ (RAS) which is 7 items, 5 point Likert scale designed to measure partner relationship satisfaction; I indicates low level of satisfaction while 5 is for high level of satisfaction. The cronbach's alpha reliability coefficient is 0.93 .

\section{RESULTS}

The study consisted of 100 females $(n=100), 50$ obese married females and 50 non-obese married females. The age range of research sample was 25 to 40 years. Mean age of married obese women was 34 years, and their husband's mean age was 39 years. Mean age of non-obese married women was 33 years and their husband's mean age was 38 years. Demographic details of the study participants are given in Table I. Reliability analysis and statistics of Body Shape Questionnaire \& Relationship Assessment Scale is given in Table II. Results of body image disturbance and relationship satisfaction between obese and non-obese married women are given in Table III. The correlation of body shape questionnaire with relationship assessment scale showed no relationship ( $r=-0.001$; $\mathrm{p}>0.05)$.

\section{DISCUSSION}

The goal of this study was to determine the association between body image disturbance and relationship satisfaction among obese and non-obese married women. This study mainly investigated the married females' body image disturbance which had impact and effect on their relationship satisfaction (marital relationship satisfaction). The results showed a significant relationship between body image disturbance and obesity status of married women. Obesity has impact on the cognition and image of individuals proved by a study that those married females who gained their weight after marriage and have disturbance in perceiving their body image had more relationship dissatisfaction in their intimacy relationships. ${ }^{19}$ Seligman MEP also evaluated that the change in body image disturbance after marriage developed dissatisfaction in martial relationships. ${ }^{20}$ Same is seen in western culture, the females there are also more concerned about their body shape and size because of its direct impact on relationship satisfaction as well as dating relationship. ${ }^{21}$ The stress to be slim and smart is important factor for those married females who gained their weight after birth of children. This tendency definitely has an impact on female self-image that has a link with marital satisfaction after perceiving husband's avoidance. ${ }^{22}$ Specifically, the social stigmatization also plays an important role for obese female's marital relationship satisfaction. O'Brien $\mathrm{KS}$, et $\mathrm{al}^{23}$ showed that media, peers, relatives and husband pressure to be slim and smart have direct impact on obese female self-perception. The study showed media impact on female's physical appearance which makes them more conscious about their own self, specifically for their life partners because they want to see their wife perfectly slim and smart. Those females who have 25.5 and more score on BMI reported to have anxious feelings about body image. ${ }^{24}$

The results indicate that the marital satisfaction is low in obese married

\section{TABLE II: RELIABILITY ANALYSIS AND STATISTICS OF SCALES OF THE SAMPLE}

\begin{tabular}{|l|c|c|c|c|}
\hline Variables & $\alpha$ & Mean & SD & No. of items \\
\hline Body Shape Questionnaire (BSQ) & 0.981 & 163.84 & 824.17 & 34 \\
\hline Relationship Assessment Scale (RAS) & 0.934 & 16.20 & 6.83 & 7 \\
\hline
\end{tabular}

TABLE III: INDEPENDENT SAMPLE T-TEST ON THE VARIABLES OF BODY IMAGE DISTURBANCE AND RELATIONSHIP SATISFACTION BETWEEN OBESE AND NON-OBESE MARRIED WOMEN $(\mathbf{N}=100)$

\begin{tabular}{|c|c|c|c|c|c|c|c|}
\hline Variables & Groups & Frequency & Mean & SD & df & $p$-value & $t$ \\
\hline \multirow{2}{*}{$\begin{array}{l}\text { Body Image } \\
\text { Disturbance }\end{array}$} & Non-Obese & 50 & 62.78 & 11.04 & \multirow{2}{*}{98} & 0.000 & \multirow{2}{*}{22.824} \\
\hline & Obese & 50 & 158.96 & 27.67 & & 0.000 & \\
\hline \multirow{2}{*}{$\begin{array}{l}\text { Relationship } \\
\text { Satisfaction }\end{array}$} & Non-Obese & 50 & 26.84 & 3.83 & \multirow{2}{*}{98} & 0.000 & \multirow{2}{*}{9.605} \\
\hline & Obese & 50 & 16.27 & 6.83 & & 0.000 & \\
\hline
\end{tabular}


women as compared to non-obese married women. Findings of this research justify that obese and overweight women have lower level of marital satisfaction as compared to those women who have normal range BMI. ${ }^{25}$ A study found that those women who have high BMI reports unhappiness in their marital life with interpersonal conflicts, whereas women with slim and smart body report a happy marital life. The findings of this study shows that the obese females have dissatisfaction in their marital life as compared to those who have normal body weight. ${ }^{26}$

The results show that body image disturbance and marital satisfaction has no relationship. Meltzer and McNulty suggested that obese married female's face multiple interpersonal conflicts, which apparently has no association with their physical appearance. It is also justified that females who have satisfied feelings in their close relationships mostly have satisfactory marital satisfaction with probably no link to body image disturbance. ${ }^{28}$ Another research evidenced that $55 \%$ Pakistani married women have weight gain problems but there is no association with marital relationship may be due to cultural, and social differences as found by Ludwig et al. ${ }^{29}$ The fact is that the most of obese women accept the negative assessment about their obesity. The association of body image disturbance and marital relationship satisfaction in obese women has no link because married women have a lot of other marital complications in their life, which do not specifically relate with their physical appearance. ${ }^{30}$

This research results suggest that Pakistani obese married women having disturbance in their body image will have the fear of separation, rejection, discomforts and abandonment in their close relationships.

\section{CONCLUSION}

Obesity has significant impact on body image and relationship satisfaction in married women. Present research proposes awareness for women with obesity; it will also be helpful in enhancing their knowledge about the nature and manageability of obesity.
Further, this study enable increased understanding of psychologist, counselor and others to psycho educate their patients diagnosed with obesity.

\section{REFERENCES}

I. World Health Organization. Obesity and overweight 2016. [Cited on: November $6^{\text {th }}, 2018$ ] Available from URL: http://www.who.int/mediacentre/f actsheets/fs3। I/en/

2. National Institute of Diabetes and Digestive and Kidney Diseases. Overweight and obesity statistics [Internet] 20I2. [Cited on: November $\left.20^{\text {th }}, 2018\right]$ Available $\mathrm{f} \mathrm{r} \circ \mathrm{m} \quad \mathrm{U} \mathrm{R}$ L: https://www.niddk.nih.gov/healthinformation/.

3. Burkhauser RV, Cawley J. Beyond BMI: the value of more accurate measures of fatness and obesity in social science research. J Health Econ 2008;27(2):519-29. DOI: 10.1016/j.jhealeco.2007.05.005.

4. Crowther NJ, Norris SA. The current waist circumference cut point used for the diagnosis of metabolic syndrome in sub-Saharan African women is not appropriate. PLoS One 20I2;7(II):e48883. DOI: I0.137I/journal.pone. 0048883.

5. Goswami S, Sachdeva S, Sachdeva R. Body image satisfaction among female college students. Ind Psychiatry J 20I2;2I(2): I68-72. DOI: I0.4 I03/0972-6748.I I 9653.

6. $\mathrm{Ng} \mathrm{M}$, Fleming $\mathrm{T}$, Robinson $\mathrm{M}$, Thomson B, Graetz N, Margono C, et al. Global, regional, and national prevalence of overweight and obesity in children and adults during 1980-2013: a systematic analysis for the Global Burden of Disease Study 2013 . The Lancet 2014 May 29;384(9945):766-8I. DOI: 10.1016/S0I40-6736(I4)60460-8.

7. Jernigan AM, Tergas Al, Satin AJ, Fader AN. Obesity management in gynecologic cancer survivors: provider practices and attitudes. Am J Obstet Gynecol 2013 May;208(5):408.el-8. DOI: 10.1016/j.ajog.2013.02.002.
8. Sallis JF, Owen N, Fische EB. Ecological models of health behavior. In Glanz K, Rimer BK, Viswanath K, editors. Health Behavior and Health Education: Theory, Research, and Practice. $4^{\text {th }}$ ed. 2008. p 465-86. JOSSEY-BASS, a wiley imprint. John Wiley \& Sons, San Francisco, USA.

9. Bandura A. A social cognitive theory of personality. In Pervin L, John O, editors. Handbook of personality. $2^{\text {nd }}$ ed. 1999. pI54-96. Guilford Publications, New York, USA.

10. Sarwer DB, Lavery M, Spitzer JC. A review of the relationships between extreme obesity, quality of life, and sexual function. Obes Surg 2012 Apr;2 2(4):668-76. DOI: I0.1007/s | |695-0|2-0588-I.

I I. Paeratakul S, White MA, Williamson DA, Ryan DH, Bray GA. Sex, race/ethnicity, socioeconomic status, and BMI in relation to self-perception of overweight. Obes Res 2002 May; I0(5):345-50. DOI: 10.1038/oby.2002.48.

12. McNulty JK, Neff LA, Karney BR. Beyond initial attraction: physical attractiveness in newlywed marriage. J Fam Psychol 2008 Feb;22(I):I35-43. DOI: 10.1037/ 0893-3200.22.I.I35.

13. Arcelus J, Yates A, Whiteley R. Romantic relationships, clinical and sub-clinical eating disorders: A review of the literature. Sex Relation Ther 2012 Jun |8;27(2):|47-6|. DOI:|0.1080/ |4681994.2012.696095.

14. Stokes R. Frederick-Recascino C. Women's perceived body image relations with personal happiness. J Women Aging 2003;I5(I): 17-29. DOI:I0.1300/J074vI5n0I_03.

15. Zawawi JA. Relationships between Body Mass Index, Body Image Dissatisfaction and Psychological Distress among Fitness Center Female Users in Zarqa-Jordan. Int J Hum Soc Sci 20 I 4;4( I): I I-20.

16. Evans C, Dolan B. Body shape questionnaire: Derivation of shortened "alternate forms". Int J Eat Disord 1993;|3(3):3|5-2|. DOI: 10.1002/1098-108X(199304) 
13:3<315::AID-EAT2260130310> 3.0.CO;2-3.

17. Keys A, Fidanza F, Karvonen MJ, Kimura N, Taylor HL. Indices of relative weight and obesity. Int J Epidemiol 20 4; 43(3):655-65. DOI: 10.1093/ije/dyu058.

18. Hendrick SS. A generic measure of relationship satisfaction. J Marriage Fam I 988;50(I):93-8. DOI: I 0.2307 1352430 .

19. AL-Otaibi HH, Naseef SL, Raouf TA. Body image dissatisfaction, weight status and physical activity among a sample of university students in Saudi Arabia. Food Nutr Sci 20I3;4(6):6|6-25. DOI:10.4236/ fns.2013.46079.

20. Seligman MEP. Positive health. Appl Psychol 2008;57(I):3-18. DOI: I 0. I I I I/j. I 464-0597.2008.0035 I.x.

21. Yamamiya Y, Cash TF, Melnyk SE, Posavac, HD, Posavac SS. Women's exposure to thin-and-beautiful media images: Body image effects of media-ideal internalization and impact-reduction interventions. Body Image 2004;2(I):74-80. DOI: I0.1016/j. bodyim. 2004 . II.00I.
22. Lovell GP, Gordon JA, Mueller MB, Mulgrew K, Sharman R. Satisfaction of Basic Psychological Needs, SelfDetermined Exercise Motivation, and Psychological Well-Being in Mothers Exercising in Group-Based Versus Individual-Based Contexts. Health Care Women Int 2016;37(5) :568-82. DOI:10.1080/07399332. 2015.1078333.

23. O'Brien KS, Latner JD, Ebneter D, Hunter JA. Obesity discrimination: the role of physical appearance, personal ideology, and anti-fat prejudice. Int J Obes (Lond) 2013 Mar;37(3):455-60.DOI: I 0.1038/ ijo.20I2.52.

24. Grant PG, Boersma H. Making sense of being fat: $A$ hermeneutic analysis of adults' explanations for obesity. Couns Psychother Res 2005;5(3):2I2-20. DOI: 10.1080/ |744|690500310429.

25. Choo J, Jeon S, Lee J. Gender differences in health-related quality of life associated with abdominal obesity in a Korean population. BMJ Open 20I 4 Jan 24;4(I):39-54. DOI: I0. I I36/bmjopen-20 I3-003954.

26. Bolton MA, Lobben I, Stern TA. The impact of body image on patient care. Prim Care Companion J Clin Psychiatry 20 I0; I 2(2):722-34. DOI: 10.4088/PCC. I Or00947blu.

27. Meltzer AL, McNulty JK. Body image and marital satisfaction: evidence for the mediating role of sexual frequency and sexual satisfaction. J Fam Psychol 20II April I;24(2):I56-64. DOI:I0. 1037/a001906.

28. Pujols Y, Seal BN, Meston CM. The association between sexual satisfaction and body image in women. J Sex Med 2010;7(2 Pt 2):905-16. DOI:10.1III/j.17436109.2009.01604.x.

29. Ludwig J, Sanbonmatsu L, Gennetian L, Adam E, Duncan GJ, Katz LF, et al. Neighborhoods, obesity, and diabetes--a randomized social experiment. $\mathrm{N}$ Eng J Med 20I I October 20;365(I6):I509-19. DOI: 10.1056/ NEJMsal 103216 .

30. Williams K. Has the future of marriage arrived? A contemporary examination of gender, marriage, and psychological well-being. J Health Soc Behav 2014 May 12;44 (4):470-87.

\section{AUTHORS' CONTRIBUTIONS}

Following authors have made substantial contributions to the manuscript as under:

SH: Concept \& study design, drafting the manuscript, critical review, final approval of the version to be published.

MZ: Acquisition of data, drafting the manuscript, final approval of the version to be published.

RY: Analysis \& interpretation of data, drafting the manuscript, final approval of the version to be published.

Authors agree to be accountable for all aspects of the work in ensuring that questions related to the accuracy or integrity of any part of the work are appropriately investigated and resolved.

\begin{tabular}{|c|}
\hline CONFLICT OF INTEREST \\
Authors declared no conflict of interest \\
GRANT SUPPORT AND FINANCIAL DISCLOSURE \\
NIL
\end{tabular}

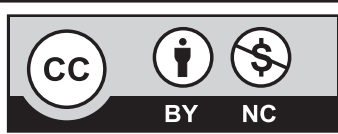

This is an Open Access article distributed under the terms of the Creative Commons Attribution-Non Commercial 2.0 Generic License. 